\title{
Comparison of Iadpsg And Dipsi Criteria for Diagnosis of Gestational Diabetes Mellitus
}

\author{
Dr.N.Geetha $\mathrm{MD}(\mathrm{OG})^{1}$, Dr.K.Gowri Sangeetha MD $(\mathrm{OG})^{2}$. \\ ${ }^{1}$ Associate Professor GMKMCH, Salem. (Author) \\ ${ }^{2}$ Assisstant Professor, GMKMCH, Salem (Coauthor)
}

\begin{abstract}
:
Aim: DIPSI (Diabetes in Pregnancy Study Group India) guidelines recommends the non-fasting 75 gms glucose tolerance test as a single step screening and diagnostic test for GDM. International Association of Diabetes and Pregnancy Study Group (IADPSG) guidelines states that when a pregnant women walks into the antenatal clinic in fasting state, fasting blood sugar has to be taken. Then $75 \mathrm{gms}$ oral glucose to be given and $1 \mathrm{hr} \& 2 \mathrm{hr}$ venous plasma glucose has to be taken. Fasting plasma glucose $\geq 92 \mathrm{mgs} / \mathrm{dl}$, $1 \mathrm{hr}$ plasma glucose $\geq 180 \mathrm{mgs} / \mathrm{dl}$ or $2 \mathrm{hr}$ plasma glucose $\geq 153 \mathrm{mgs} / \mathrm{dl}$ diagnoses GDM. Our objective was to study the implications of implementing the IADPSG guidelines and DIPSI guidelines for screening and diagnosis of GDM in Indian population.

Method: Prospective study of a total of 100 pregnant women attending AN clinic at GMKMCH, Salem from February 2016 to august 2016 underwent a 75 gms OGTT in non-fasting state. Then after 2-3 days apart fasting, after $75 \mathrm{gms}$ glucose load $1 \mathrm{hr} \& 2 \mathrm{hr}$ plasma glucose was taken. Venous plasma glucose was measured using an auto analyser and GDM was diagnosed by DIPSI and IADPSG criteria.

Results: Among them 14\% were diagnosed by DIPSI criteria. $9 \%$ were diagnosed by IADPSG criteria.4\% were diagnosed by both. Diagnosis of GDM by IADPSG criteria leaves 5\% undiagnosed which may be easily detected through DIPSI. Eventhough the DIPSI criteria detects more number of cases than IADPSG criteria, it is not statically significant. Because DIPSI method is practically easier to do which also detects more number of cases, it is better than IADPSG method.
\end{abstract}

Keywords: DIPSI, IADPSG, GDM

\section{Introduction}

GDM is an important public health problem. Its prevalence is increasing as obesity, sedentary lifestyle and older age at pregnancy become more common. GDM is defined as carbohydrate intolerance of variable severity within its onset or first recognition during pregnancy. Pregnancy is a form of stress that can cause latent diabetes to manifest just as do surgical operations or acute infections. In most of the cases, the carbohydrate intolerance will revert by the end of puerperium. Women with GDM, though are at increased risk of pregnancy complications like pre-eclampsia, hydramnios, preterm labour and still birth, remains asymptomatic otherwise and hence screening of pregnant women for GDM is a must. Since our ethnicity is at high risk, all pregnant women should ideally undergo screening at $24-28$ wks of gestation. Unfortunately, there is no international consensus on the screening and diagnostic criteria for GDM. In 1999, WHO introduced criteria for diagnosis of GDM on the basis of $2 \mathrm{hr}$ venous plasma glucose cutoff value of $140 \mathrm{mgs} / \mathrm{dl}(7.8 \mathrm{mmol} / \mathrm{L})$ after the administration of $75 \mathrm{gms}$ of glucose. It is very popular because it is a single step procedure. In 2010 , based on the hyperglycemia and adverse pregnancy outcome(HAPO) study, fasting blood sugar to be taken. Then $75 \mathrm{gms}$ of oral glucose load given, $1 \mathrm{hr}$ and $2 \mathrm{hr}$ venous blood glucose to be taken. If Fasting plasma glucose $\geq$ $92 \mathrm{mgs} / \mathrm{dl}(5.1 \mathrm{mmol} / \mathrm{l}), 1 \mathrm{hr}$ plasma glucose $\geq 180 \mathrm{mgs} / \mathrm{dl}(10 \mathrm{mmol} / \mathrm{l})$, $2 \mathrm{hrplasma}$ glucose $\geq 153 \mathrm{mgs} / \mathrm{dl}($ $8.5 \mathrm{mmol} / \mathrm{l})$, GDM is diagnosed. Our objective was to study the implications of implementing the IADPSG guidelines or DIPSI guidelines for screening and diagnosis of GDM.

\section{Methods}

The aim of the study was to compare the sensitivity \& specificity of DIPSI criteria \& IADPSG criteria in the diagnosis of GDM in order to assess whether fasting OGTT is better than non fasting OGTT though somewhat difficult. This study was made in GMKMCH, Salem for those women attending antenatal clinic between $24-28$ wks of gestation. The study was conducted between February 2016 to august2016 for around 100 cases.

A standardised questionnaire was given that includes Name, Address, Age, any family h/o diabetes (father/mother/others). height, weight \& BMI was measured, Any previous $\mathrm{H} / \mathrm{o}$ of $\mathrm{BOH}$, hypertension, thyroid, previous H/o GDM, delivery of baby more than $3.5 \mathrm{~kg}$ was asked. All participants was asked to give informed written consent after explaining the study. The study was approved by Ethical committee,Government Mohan 
Kumaramangalam Medical College, Salem. Around 100 antenatal women attending the antenatal clinics in the non -fasting state underwent a non-fasting OGTT using $75 \mathrm{gms}$ of anhydrous glucose irrespective of the time of last meal, $2 \mathrm{hrs}$ later, a venous blood sample was taken. All the 100 women who had undergone non-fasting OGTT were requested to return after 3 to 4 days later to undergo fasting OGTT. The patients must come after an overnight fasting of atleast $8 \mathrm{hrs}$. Fasting, $1 \mathrm{hr}, 2 \mathrm{hr}$ venous blood samples were taken. Blood samples were collected in sodium fluoride/ Na2EDTA tubes to prevent glycolysis. Plasma glucose was measured using an autoanalyser. If non-fasting OGTT $\geq 140 \mathrm{mgs} / \mathrm{dl}$ then DIPSI criteria is positive. If fasting $\geq 92 \mathrm{mgs} / \mathrm{dl}, 1 \mathrm{hr} \geq$ $180 \mathrm{mgs} / \mathrm{dl}$ and $2 \mathrm{hr} \geq 153 \mathrm{mgs} / \mathrm{dl}$ then IADPSG criteria is positive.

\section{Statistical Analysis And Results}

All values are expressed as the mean \& SD. Statistical analysis was performed by chi square test The results of 100 women were analysed in the study. The mean age of 100 women is 24.6 years The mean BMI is 25.55. The mean gestational age is 25.57 weeks .

\begin{tabular}{|c|c|c|c|c|c|}
\hline \multicolumn{2}{|c|}{ Gravida } & \multicolumn{2}{|r|}{ Frequency } & \multicolumn{2}{|r|}{ Percent } \\
\hline \multicolumn{2}{|c|}{ Primi } & \multicolumn{2}{|r|}{38} & \multicolumn{2}{|r|}{38} \\
\hline \multicolumn{2}{|c|}{$\mathrm{G} 2$} & \multicolumn{2}{|r|}{34} & \multicolumn{2}{|r|}{34} \\
\hline \multicolumn{2}{|c|}{ G3 } & \multicolumn{2}{|r|}{20} & \multicolumn{2}{|r|}{20} \\
\hline \multicolumn{2}{|c|}{ G4 } & \multicolumn{2}{|r|}{6} & \multicolumn{2}{|r|}{6} \\
\hline \multicolumn{2}{|c|}{ G5 } & \multicolumn{2}{|r|}{2} & \multicolumn{2}{|r|}{2} \\
\hline \multicolumn{2}{|c|}{ Total } & \multicolumn{2}{|r|}{100} & \multicolumn{2}{|r|}{100} \\
\hline & $\mathbf{N}$ & Minimum & Maximum & Mean & Std Deviation \\
\hline Age & 100 & 19 & 40 & 24.63 & 4.27 \\
\hline $\mathrm{Ht}(\mathrm{cm})$ & 100 & 140 & 168 & 153.07 & 5.93 \\
\hline $\mathrm{Wt}(\mathrm{kg})$ & 100 & 48 & 86 & 59.80 & 7.48 \\
\hline BMI & 100 & 20.2 & 34.19 & 25.55 & 2.99 \\
\hline GA & 100 & 24.00 & 28.00 & 25.57 & 1.55 \\
\hline
\end{tabular}

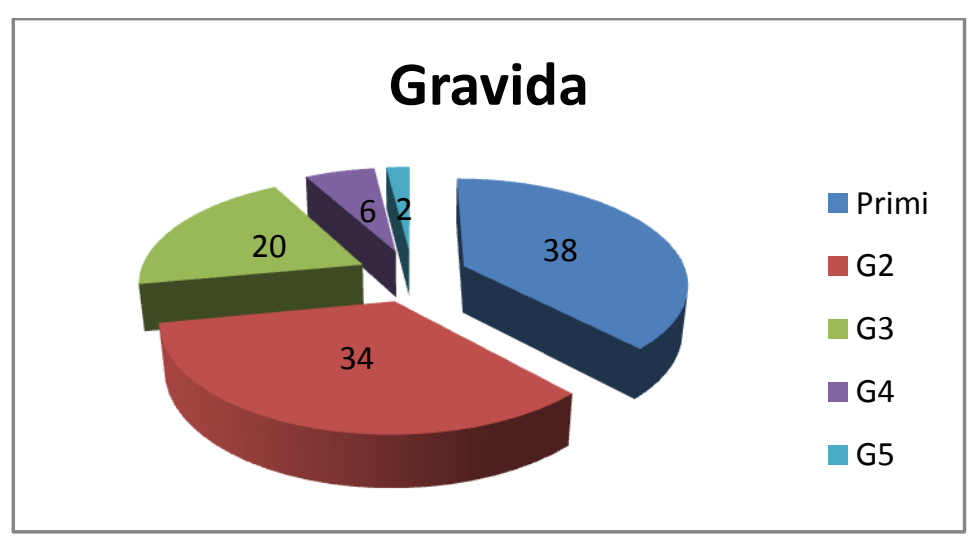

Among the 100 women 38 were primigravida and others were multigravida

\begin{tabular}{|c|c|c|}
\hline DIPSI & Frequency & Percent \\
\hline Positive & 14 & 14 \\
\hline Negative & 86 & 86 \\
\hline Total & 100 & 100 \\
\hline
\end{tabular}

\begin{tabular}{|c|c|c|}
\hline IADPSG & Frequency & Percent \\
\hline Positive & 9 & 9 \\
\hline Negative & 91 & 91 \\
\hline Total & 100 & 100 \\
\hline
\end{tabular}

\begin{tabular}{|c|c|c|c|c|c|c|c|}
\hline & \multicolumn{2}{|c|}{ Positive } & \multicolumn{2}{|c|}{ Negative } & \multirow{2}{*}{ Total } & \multirow{2}{*}{$\begin{array}{c}\text { Chi } \\
\text { square }\end{array}$} & \multirow{2}{*}{$\mathbf{p}$} \\
\hline & $\mathbf{N}$ & $\%$ & $\mathbf{N}$ & $\%$ & & & \\
\hline DIPSI & 14 & 14 & 86 & 86 & 100 & \multirow{2}{*}{1.23} & \multirow{2}{*}{0.268} \\
\hline IADPSG & 9 & 9 & 91 & 91 & 100 & & \\
\hline
\end{tabular}




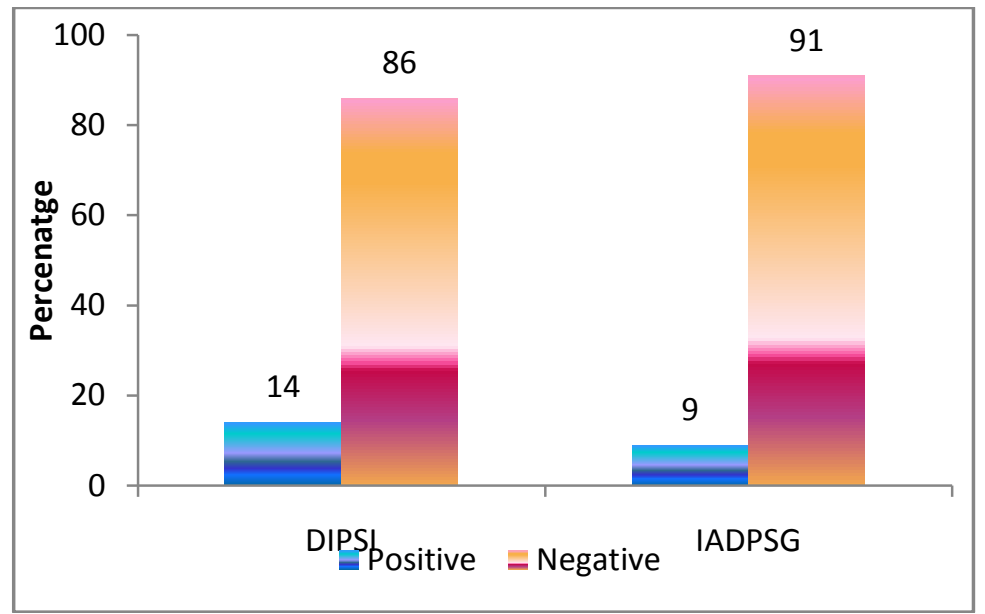

$14 \%$ were diagnosed to have GDM using DIPSI criteria. There were no difference in age, duration of gestation ,BMI or first degree family history diabetes between DIPSI and IADPSG criteria Out of 14 women identified to have GDM by DIPSI criteria, only 4 women diagnosed by IADPSG criteria,10 9 women were diagnosed by IADPSG criteria. Of the 9 women diagnosed by IADPSG criteria, 5 women were left by DIPSI criteria.

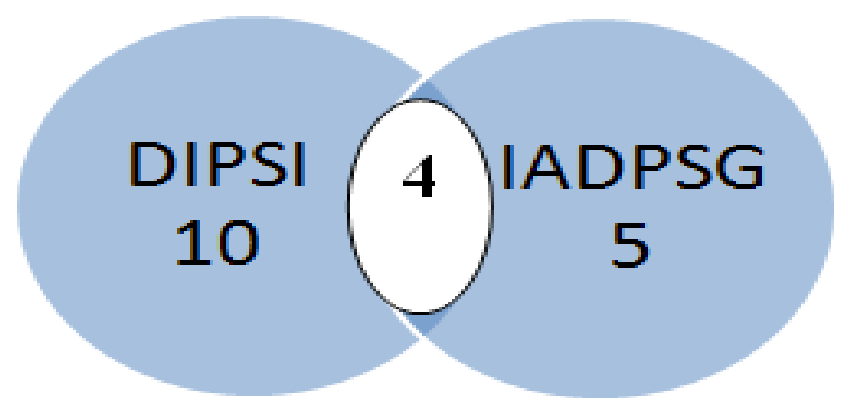

On comparing the DIPSI with IADPSG, the sensitivity of DIPSI was greater than IADPSG.

\section{Discussion}

The DIPSI guidelines for diagnosis of GDM is $2 \mathrm{hr}$ non-fasting OGTT $\geq 140 \mathrm{mgs} / \mathrm{dl}(7.8 \mathrm{mmol} / \mathrm{L}) \&$ it can be used as a single step, definitive, screening and diagnostgic test for GDM. These guidelines were based on a single centre study from South India which reported $100 \%$ sensitivity \& $100 \%$ specificity compared to WHO 1999 criteria. The DIPSI guidelines have been widely accepted and being used all over India. IADPSG guidelines Fasting $\geq 92 \mathrm{mgs} / \mathrm{dl}$, $1 \mathrm{hrpostprandial} \geq 180 \mathrm{mgs} / \mathrm{dl}, 2 \mathrm{hr}$ postprandial $\geq 153 \mathrm{mgs} / \mathrm{dl}$ as GDM. This study shows that non-fasting OGTT has higher sensitivity but it is not statistically significant. Thus the current DIPSI guidelines of doing a single step non-fasting OGTT using $2 \mathrm{hr}$ venous plasma glucose of $140 \mathrm{mgs} / \mathrm{dl}$ to diagnose GDM is better than IADPSG criteria, In developing countries like India, women has to come travelling long distance for checkup, hence second test which is a difficult task. Based on the findings of this study, DIPSI criteria can be used for a single step screening \& diagnostic criteria than IADPSG criteria.

\section{Conclusion}

DIPSI method is practically easier to do as it is a single step procedure and also tolerance of the patient to glucose drinking is better in non fasting state. Patients need not come in fasting state. Also for IADPSG criteria to be adopted, it needs more laboratory support, extra time and extra cost.

Hence in our set up, diagnosis of GDM by DIPSI criteria is better than IADPSG criteria.

\section{References}

[1]. Metzger BE. Organizing committee: summary and recommendations of the third international workshop conference on gestational diabetes mellitus. Diabetes. 1991;40 Suppl 2:197-201.

[2]. HAPO Study Cooperative Research Group. Hyperglycemia and ad- verse pregnancy outcomes. N Eng1 J Med. 08;358:1991-

[3]. 2002

[4]. Seshiah V, Balaji V, Balaji S, Sanjeevi CB. Gestational diabetes mellitus in India. JAPI. 2004;52:707-11.

[5]. Agarwal S, Gupta AN. Gestational diabetes. J Assoc Physicians India. 1982;30:203. 
[6]. Narendra J, Munichoodappa C, Gurudas A, Ramprasad AV,Madhav T, Vijayalakshmi, et al. Prevalence of glucose intolerance during pregnancy. Int J Diab Dev Countries. 1991;11:2-4

[7]. Madsen JK, Haunsoe S, Helquist S, Hommel E, Malthe I, Pedersen NT, et al. Prevalence of hyperglycaemia and undiagnosed diabetes mellitus in patients with acute myocardial infarction. Acta Med Scand. 1986;220:329-32.

[8]. Zargar AH, Sheikh MI, Bashir MI, Masoodi SR, Laway BA, Wani AI, et al. Prevalence of gestational diabetes mellitus in Kashmiri

[9]. women from the Indian subcontinent. Diabetes Res Clin Pract. 2004;66:139-45

[10]. Metzger BE. Organizing committee: summary and recommendations of the third international workshop conference on gestational diabetes mellitus. Diabetes. 1991;40 Suppl 2:197-201.

[11]. HAPO Study Cooperative Research Group. Hyperglycemia and ad- verse pregnancy outcomes. N Engl J Med. 08;358:19912002.

[12]. Seshiah V, Balaji V, Balaji S, Sanjeevi CB. Gestational diabetes mellitus in India. JAPI. 2004;52:707-11.4. Agarwal S, Gupta AN. Gestational diabetes. J Assoc Physicians India. 1982;30:203.

[13]. Narendra J, Munichoodappa C, Gurudas A, Ramprasad AV,Madhav T, Vijayalakshmi, et al. Prevalence of glucose intolerance during pregnancy. Int J Diab Dev Countries. 1991;11:2-4

[14]. Madsen JK, Haunsoe S, Helquist S, Hommel E, Malthe I, Pedersen NT, et al. Prevalence of hyperglycaemia and undiagnosed diabetes mellitus in patients with acute myocardial infarction. Acta Med Scand. 1986;220:329-32.

[15]. Zargar AH, Sheikh MI, Bashir MI, Masoodi SR, Laway BA, Wani AI, et al. Prevalence of gestational diabetes mellitus in Kashmiri women from the Indian subcontinent. Diabetes Res Clin Pract. 2004;66:139-45

[16]. Metzger BE. Organizing committee: summary and recommendations Metzger BE. Organizing committee: summary aommendations

[17]. HAPO Study Cooperative Research Group. Hyperglycemia and adverse pregnancy outcomes. N Engl J Med. 2008;358:19912002.

[18]. Seshiah V, Balaji V, Balaji S, Sanjeevi CB. Gestational diabetes mellitus in India. JAPI. 2004;52:707-11.

[19]. Agarwal S, Gupta AN. Gestational diabetes. J Assoc Physicians India. 1982;30:203.

[20]. Narendra J, Munichoodappa C, Gurudas A, Ramprasad AV,Madhav T, Vijayalakshmi, et al. Prevalence of glucose intolerance during pregnancy. Int J Diab Dev Countries. 1991;11:2-4.

[21]. Madsen JK, Haunsoe S, Helquist S, Hommel E, Malthe I, Pedersen NT, et al. Prevalence of hyperglycaemia and undiagnosed diabetes mellitus in patients with acute myocardial infarction. Acta Med Scand. 1986;220:329-32.

[22]. Zargar AH, Sheikh MI, Bashir MI, Masoodi SR, Laway BA, Wani AI, et al. Prevalence of gestational diabetes mellitus in Kashmiri women from the Indian subcontinent. Diabetes Res Clin Pract. 2004;66:139-45.

[23]. International Association of Diabetes and Pregnancy Study Groups (IADPSG). Recommendations on the diagnosis and classification of hyperglycemia in pregnancy. IADPSG consensus panel. Diabetes Care. 2010;33:676-82.

[24]. Seshiah V, Balaji V, Shahc S, Joshid S, Dase AK, Sahayf BK, et al. Diagnosis of gestational diabetes mellitus in the community. JAPI. 2012;60:15-7. 